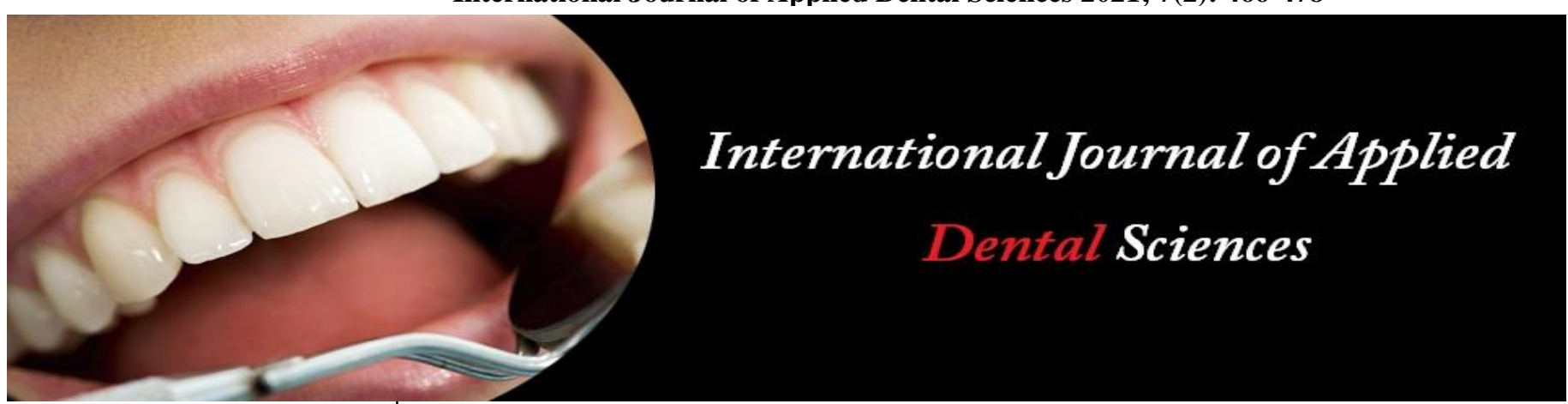

ISSN Print: 2394-7489

ISSN Online: 2394-7497

IJADS 2021; 7(2): 466-478

(C) 2021 IJADS

www.oraljournal.com

Received: 05-02-2021

Accepted: 22-03-2021

Dr. Divyashree R

BDS, MDS,

Department of Pedodontics Working as Pedodontic consultant in Kirti Eye and dental Hospital, Bangalore,

Karnataka, India
Corresponding Author: Dr. Divyashree R BDS, MDS,

Department of Pedodontics Working as Pedodontic consultant in Kirti Eye and dental Hospital, Bangalore, Karnataka, India

\section{Effectiveness of Silver Diamine Fluoride when used as an indirect pulp therapy (IPT) material- A clinical and radiological assessment}

\section{Dr. Divyashree R}

DOI: https://doi.org/10.22271/oral.2021.v7.i2g.1255

\section{Abstract}

Aim of the study: The present study assessed and compared the success of an IPT procedure both clinically and radiographically when Dycal, MTA and Silver Diamine Fluoride (SDF) were used as an IPT material on primary molars.

Methodology: Children aged 5- 9 years were screened and those who fulfilled the inclusion criteria were selected. Accordingly seventy five children were divided into 3 groups with 25 patient in each group. Cavity preparation was done and the three test materials (Dycal, MTA and SDF) were placed at the base in their respective groups and restored with RMGIC. Post-operative radiograph was taken for baseline data. Patients were assessed at Subsequent at 1, 3 and 6 months both clinically and radiographically.

Results: SDF had formed a good biological seal, arrested further caries progression and did not cause any adverse pulpal reaction. However the amount of reparative dentin formed was highest in the Dycal group followed by MTA group and SDF group.

Keywords: Silver Diamine Fluoride, Pulp Therapy, Radiological

\section{Introduction}

Indirect pulp capping has been described as a conservative alternative treatment of the dentinpulp complex, for primary and permanent teeth, since 1859 by John Tomes. The ADA defines this procedure as a "Procedure in which the nearly exposed pulp is covered with a protective dressing to protect the pulp from additional injury and to promote healing and repair via formation of tertiary dentin." It is a procedure in which the non-remineralizable tissue is removed and a thin layer of caries is left in the deepest sites of the cavity thereby avoiding the possibility of a pulp exposure ${ }^{[1]}$.

Traditionally various materials have been used for Indirect Pulp therapy procedure like Calcium hydroxide,Corticosteroids, Bonding agents, Cyanoacrylates, MTA, Lasers etc. Historically, Calcium hydroxide has been a gold standard for pulp capping ${ }^{[2]}$. The popularity of Calcium hydroxide and calcium oxide based materials for direct and indirect pulp capping is due to their ability to release hydroxyl and calcium ions upon dissolution ${ }^{[3]}$. Many commercial products of calcium hydroxide are available in the market for Indirect Pulp treatment among which Dycal is the most preferred. Dycal is a self-setting radiopaque calcium hydroxide-based material employed in direct and indirect pulp capping procedures and as a liner under restorations, cements and other base materials ${ }^{[4]}$.

Unfortunately, this material has some disadvantages like solubility, degradation over time, tunnel defects through dentinal bridges under it, poor sealing properties and raise in the local $\mathrm{pH}$ with the formation of a necrotic layer at the material-pulp interface ${ }^{[5]}$. There is a weaker chemical effect on the sub adjacent and apical tissue which results in a zone of coagulation necrosis ${ }^{[6]}$. Considering these disadvantages of calcium hydroxide products the quest for better materials continued.

Dr. Mahmoud Torabinejad in 1990's at the Loma Linda university developed Mineral Trioxide Aggregate (MTA) cement as a root end filling material. The major constituents of this material is dicalcium silicate, tricalcium silicate, and tricalcium aluminate \& tetra calcium aluminoferrite \& bismuth oxide. MTA exhibits calcified tissue-conductive activity and facilitate 
the differentiation of human Orofacial mesenchymal stem cells. It has the potential to facilitate mineralization process in human dental pulp which makes it successful to be used as an effective pulp capping agent ${ }^{[7]}$.

With the advent of technology and quest for newer material has prompted the clinicians to explore the remineralizing abilities of various other materials like Stem cells, Propolis, Bio dentine and Emdogain so on so forth.

Interest in the use of Silver Diamine Fluoride (SDF) has been growing. SDF has been used as an alternative treatment for caries prevention and arrest ${ }^{[8]}$. In vitro studies have demonstrated that SDF increases the $\mathrm{pH}$ of biofilm, reduces dentin demineralization, and has antimicrobial action against cariogenic bacteria ${ }^{[9]}$. Ex vivo and in vivo studies on cavitated extracted teeth from children receiving semi-annual applications of SDF have shown effectiveness in arresting lesions as well as higher fluoride uptake compared to fluoride varnish and acidulated phosphate fluoride gel ${ }^{[10]}$.

Clinical studies have demonstrated the effectiveness of SDF in childhood caries prevention and arrest. Semi-annual applications of SDF at $38 \%$ concentration have been recommended ${ }^{[11]}$. SDF has been suggested for difficult-totreat lesions and patients with high caries risk, including those with medical or behavioural complications, those who require multiple treatment visits, or those without access to dental care $^{[12]}$.

A study by Korwae et al. reports that SDF when used as IPT material showed no pulpal inflammatory response and detected tertiary dentin formation under a histopathological study ${ }^{[13]}$.

However, there is a paucity in literature of studies explain the long term success of SDF being used as an Indirect Pulp Capping material and also comparing the effects of Dycal, MTA and SDF when used as IPT materials for primary teeth. Hence, this study is being undertaken to evaluate the clinical and radiographic success and thereby evaluating these materials when used as an IPT material.

\section{Aim}

To evaluate the success of SDF (Silver Diamine Fluoride) when used as Indirect Pulp Capping (IPT) materials for primary teeth.

\section{Objectives}

1. To assess the reparative dentine formation of $\mathrm{Ca}(\mathrm{OH})_{2}$, MTA and SDF when used as IPT material both clinically and radiographically.

2. To compare the reparative dentine formation of $\mathrm{Ca}$ $(\mathrm{OH})_{2}$, MTA and SDF when used as IPT material both clinically and radiographically

\section{Materials and Methodology \\ Armamentarium}

1. Disposable Surgeon's cap (Dispodent)

2. Mouth mask (Suraksha)

3. Sterile gloves (Dispodent)

4. Mouth mirror and Explorer.

5. Pair of tweezers

6. Cotton rolls

7. Single use syringe-2 $\mathrm{ml}$ (Uniolok)

8. Local Anesthesia - (Lignox 2\% - Lignocaine hydrochloride $2 \%$ with 1:80,000 adrenaline)

9. Rubber Dam (Hygienic-Dental Dam kit)

10. Saliva ejection tips

11. Spoon Excavator
12. Contra angle aerotor handpiece (NSK)

13. Round Diamond Dental Burs (Mani-No 2 \& 4)

14. Calcium hydroxide (Dycal, Dentsply)

15. Ball ended condenser tip

16. MTA (Angelus)

17. Amalgam carrier

18. Silver Diamine Fluoride (SDF) (Advantage Arrest)

19. Resin Modified Glass Ionomer Cement (RMGIC)

20. Agate spatula

21. Articulating paper

22. PSP sensor plate

23. PSP scanner (Digora)

24. Position Indicating Device (XCP Holder)

\section{Study Design}

The present study was a randomized controlled in vivo study between Dycal, MTA and Silver Diamine Fluoride (SDF) as indirect pulp capping agents in primary molars.

\section{Study Setting}

The present study was done in a clinical set up in the Department of Pedodontics \& Preventive Dentistry, D. A. P. M. R V Dental College, Bangalore, and Karnataka.

\section{Source of Data}

The present in vivo study was conducted on 75 children in the age group of 6-9 years of both sexes, who visited the Department of Pedodontics and Preventive Dentistry

\section{Sample Selection}

The sample size included 75 primary molars indicated for indirect pulp capping procedure. The study subjects were randomly divided into three groups of carrying 25 teeth each according to the indirect pulp capping agents used.

Group 1 - Dycal (25 teeth)

Group 2 - MTA (25 teeth)

Group 3 - Silver Diamine Fluoride (SDF) (25 teeth)

\section{Method of Collection of Data}

The samples to each group were selected using random sampling technique.

\section{Clinical}

\section{Inclusion Criteria}

1. History of tolerable dull intermittent pain, mild discomfort associated with eating, negative history of spontaneous extreme pain.

2. On clinical examination, large carious lesions involving either the occlusal or proximal surfaces, with normal appearances of gingiva.

3. Radiographic examination showing carious lesion

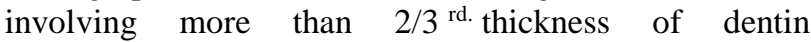
approximating the pulp, normal lamina dura, normal periodontal ligament space, more than $2 / 3^{\text {rd. }}$ of root present, no periapical changes, no pathologic external or internal resorption.

\section{Exclusion Criteria}

1. History of sharp, penetrating pulpalgia indicating acute pulpal inflammation and necrosis, prolonged spontaneous pain at night.

2. Clinical examination showing presence of mobility of tooth, discoloration of tooth, negative reaction to electric pulp testing, sinus opening, or abscessed tooth.

3. Radiographic examination showing carious lesion with 
definite pulp exposure, interrupted or broken lamina dura, widened periodontal ligament space, periapical radiolucency, internal or external resorption.

\section{Methodology and Clinical Procedure}

Patients were screened initially to determine whether they met the study inclusion criteria and thus the qualified patients were enrolled in the study.

Informed parental and patient consent and ethical clearance was taken from the Institutional Ethical Committee.

A total of 75 subjects were divided into three group based on random sampling method:

\section{Groups}

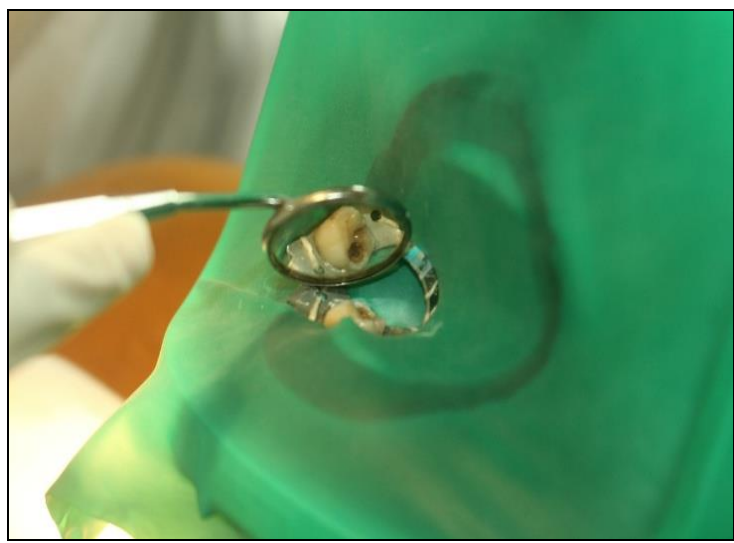

Fig 1a: Deep Carious lesion

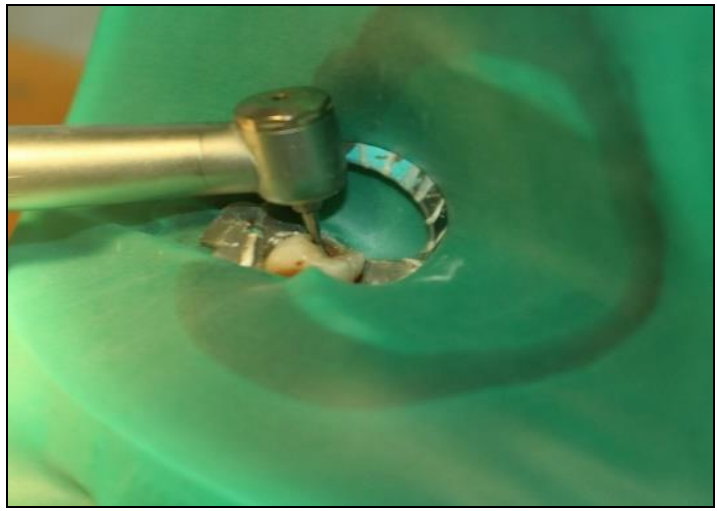

Fig 1c: Deep Caries removal

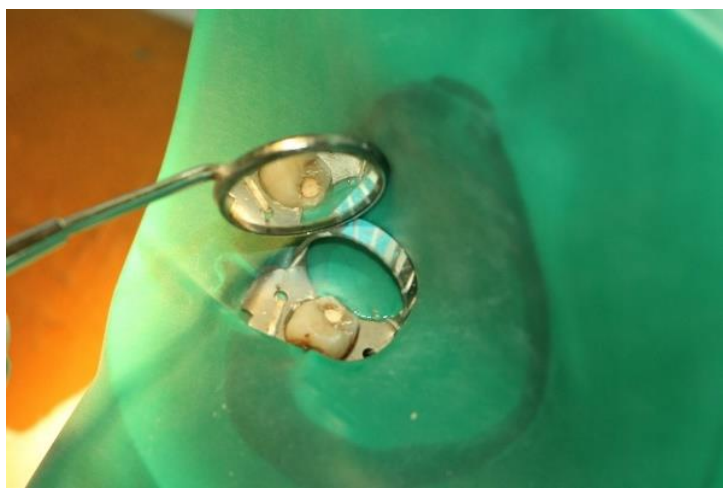

Fig 1e: Dycal base placed
Group I - 25 subjects (Dycal group)

Group II - 25 subjects (MTA group)

Group III - 25 subjects (Silver Diamine Fluoride group)

After screening profound administration of local anaesthesia using LIGNOX 2\% (Lignocaine hydrochloride 2\% with 1:80,000 adrenaline) was done and the tooth was isolated with rubber dam (Hygenic). The caries was removed either by a spoon excavator or round diamond dental bur (no 2) using a hand piece running at a slow speed $\&$ copious water irrigation leaving behind the affected dentin.

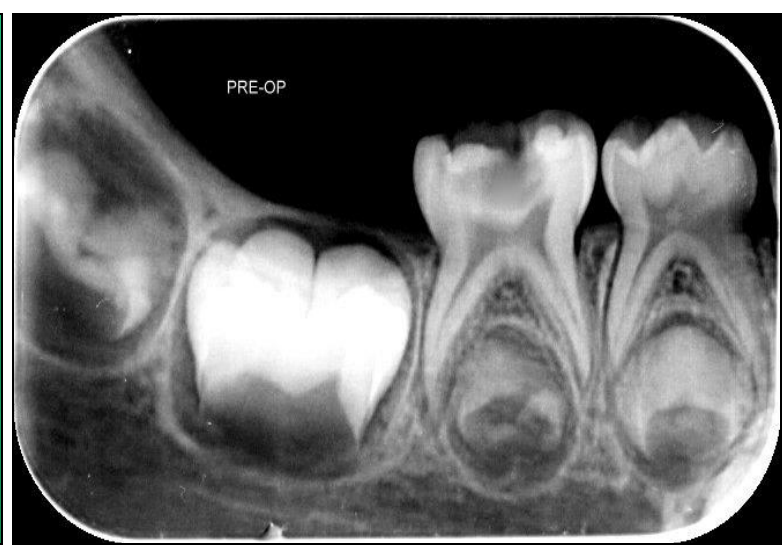

Fig 1b: Pre-Operative Radiograph

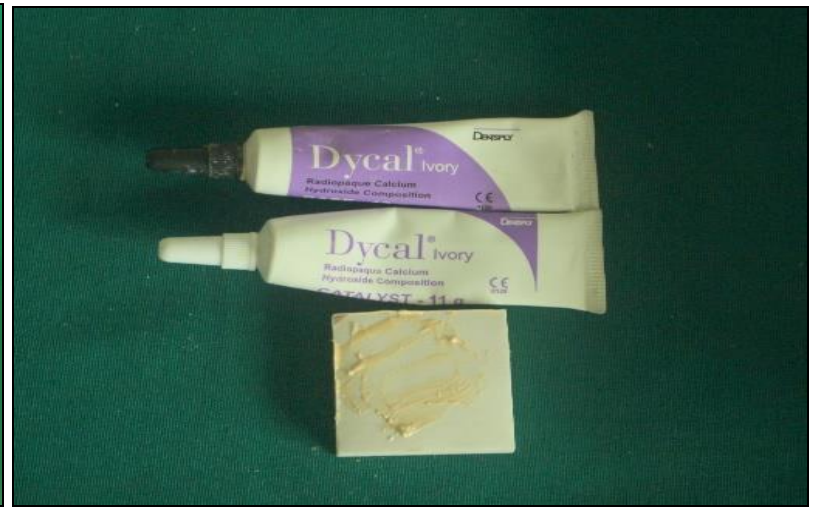

Fig 1d: Dycal mixed

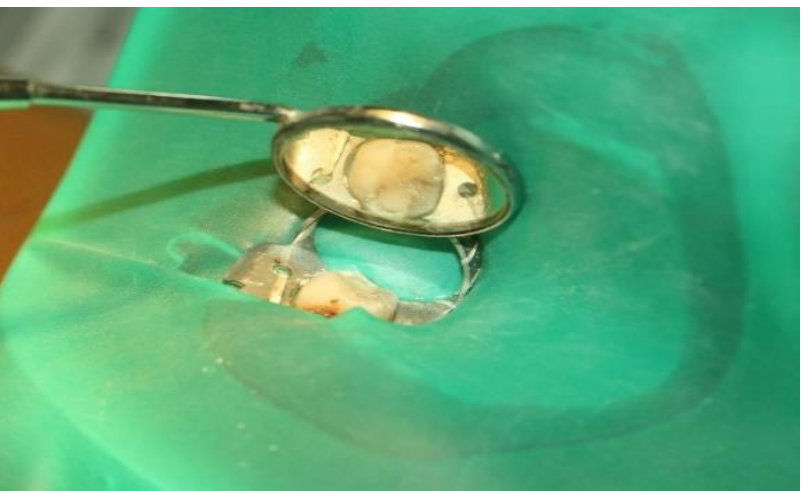

Fig 1g: Final restoration done with Type IX GIC

Group 1: Dycal

\section{Group 1: Dycal group}

Following caries removal, Calcium hydroxide (Dycal) was mixed with equal quantities of both the catalyst and the base paste to a homogenous mix according to the manufacturer's instructions and was applied to the base of the cavity using a ball ended condenser. 


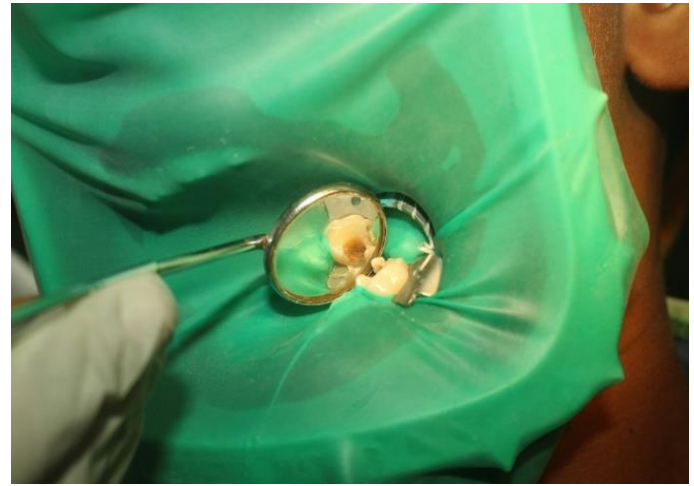

Fig 2a: Deep Carious lesion

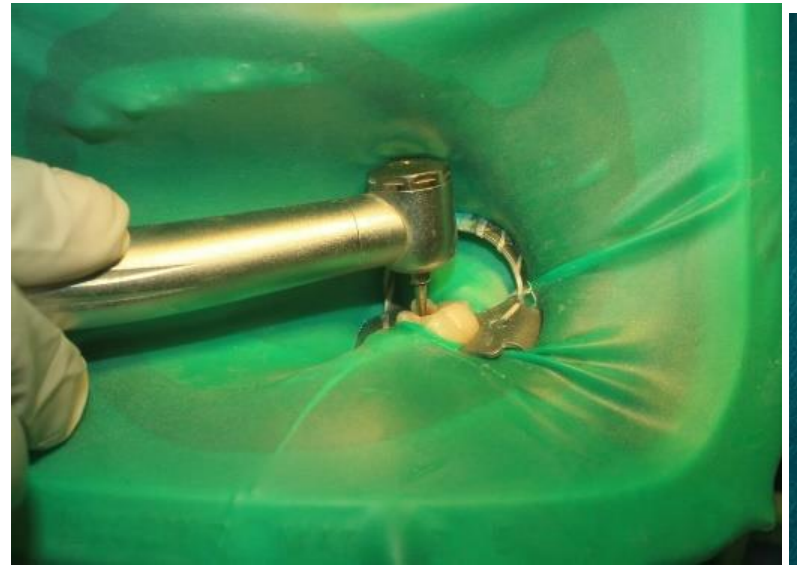

Fig 2c: Caries excavation done

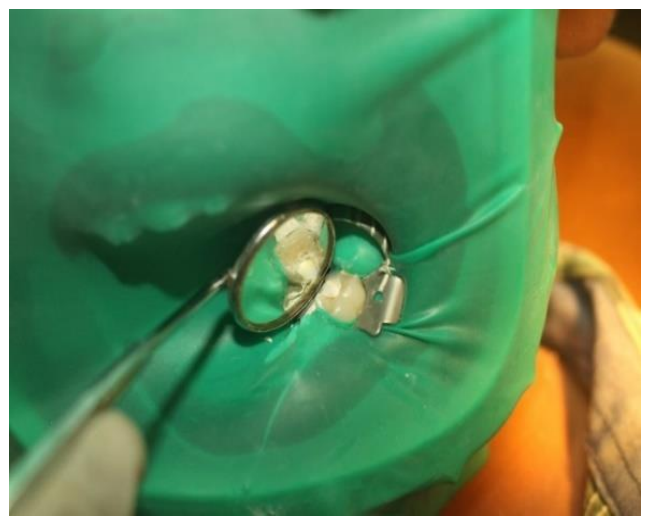

Fig 2e: MTA base placed

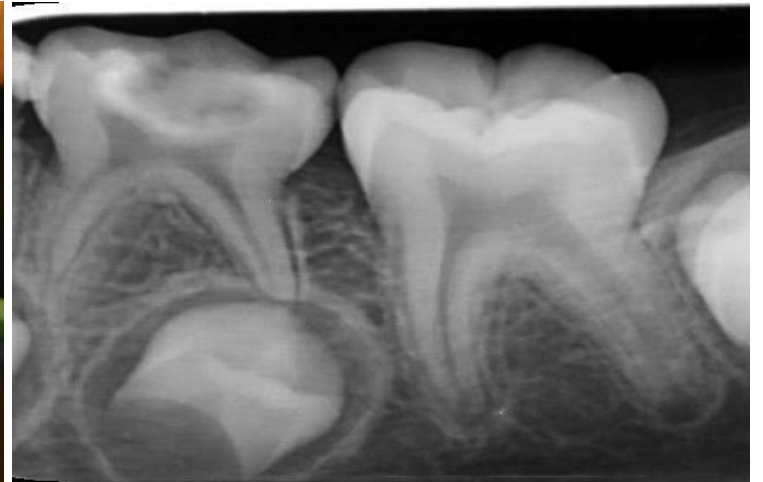

Fig 2b: Pre-operative radiograph

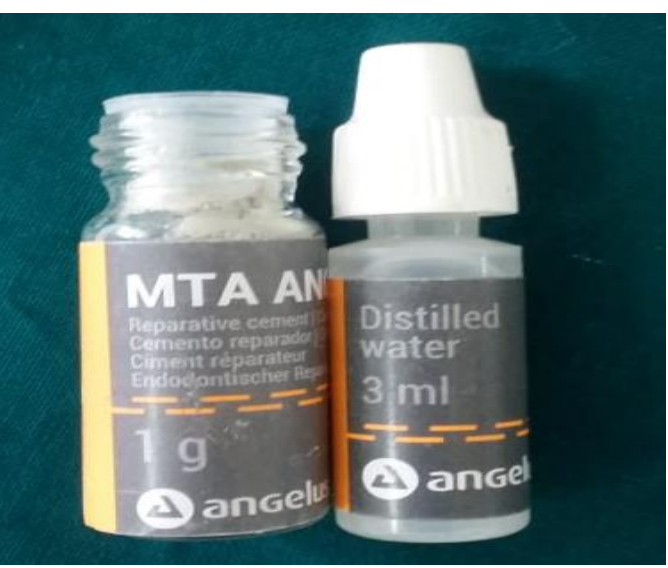

Fig 2d: MTA

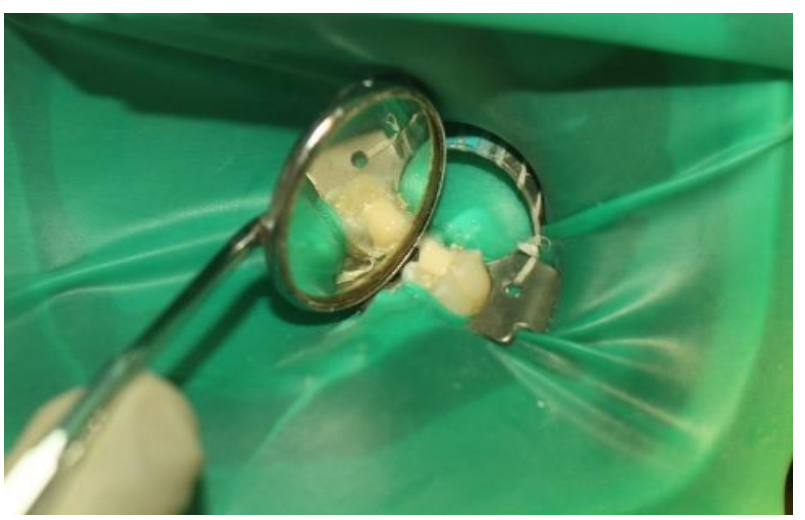

Fig 2f: Final restoration with RMGIC

Group 2- MTA

\section{Group 2: MTA group}

Following caries removal, MTA powder was mixed with sterile water for 30 seconds so as to get a sandy consistency according to the manufacturer's instructions and was placed on the floor of the cavity using an amalgam carrier. It was adapted using light pressure with moist cotton pellets.

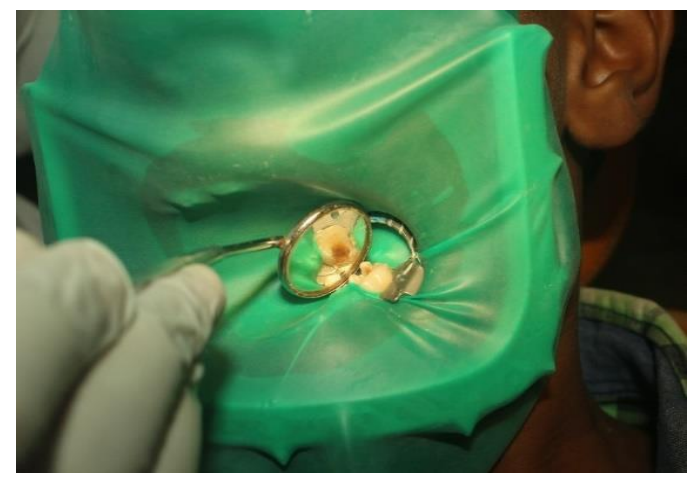

Fig 3a: Deep Carious lesion

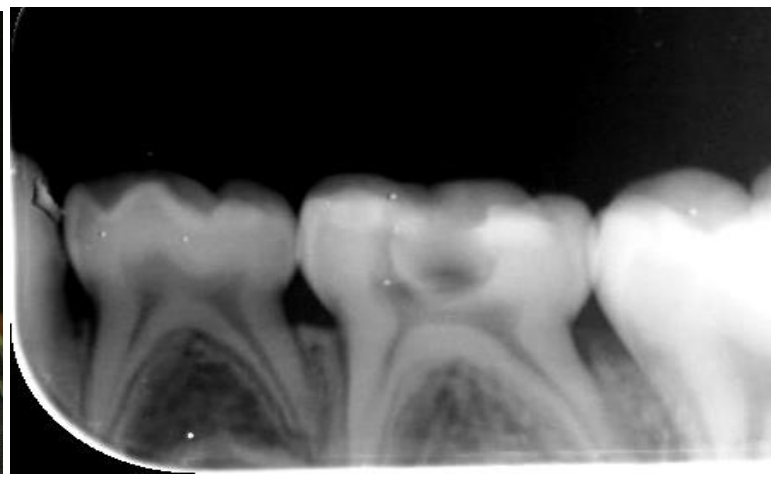

Fig 3b: Pre-Operative Radiograph 


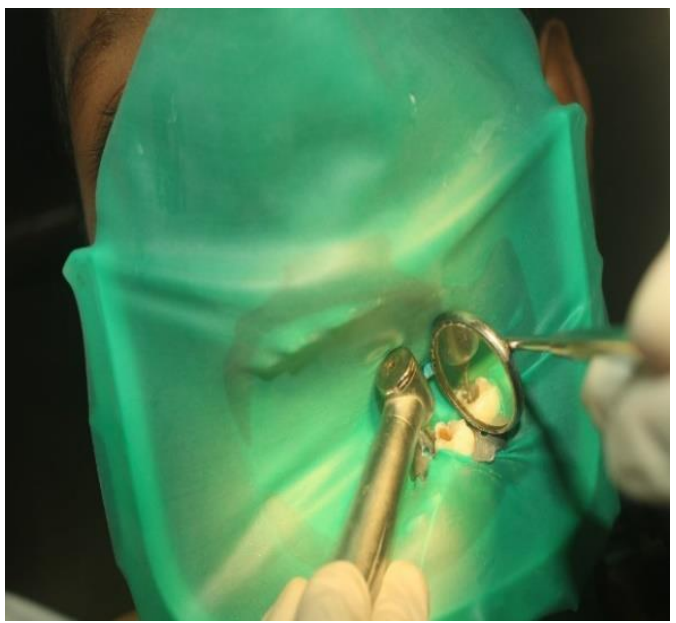

Fig 3c: Deep caries removal

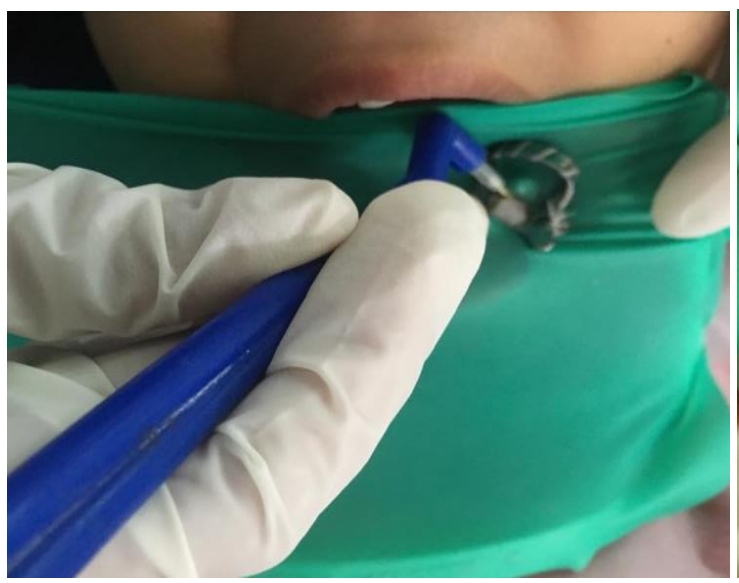

Fig 3e: SDF coating done to the base

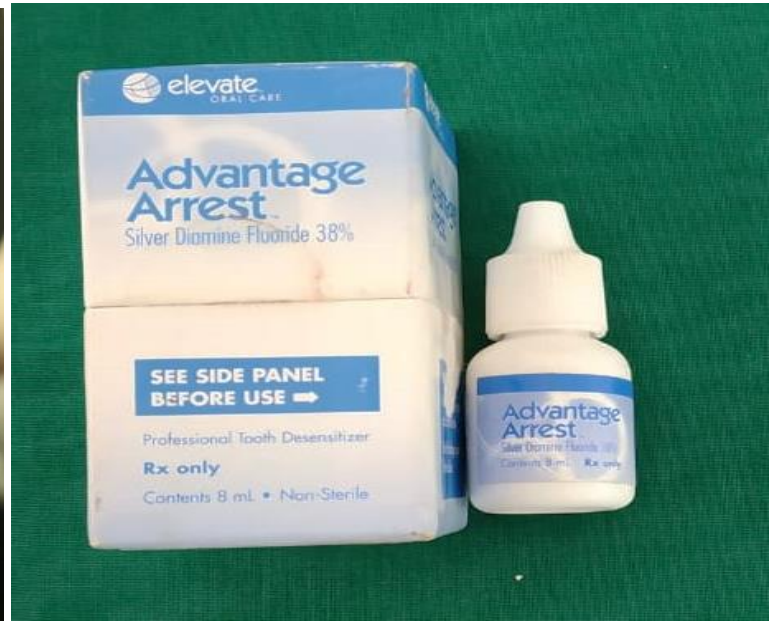

Fig 3d: SDF coating done to the base

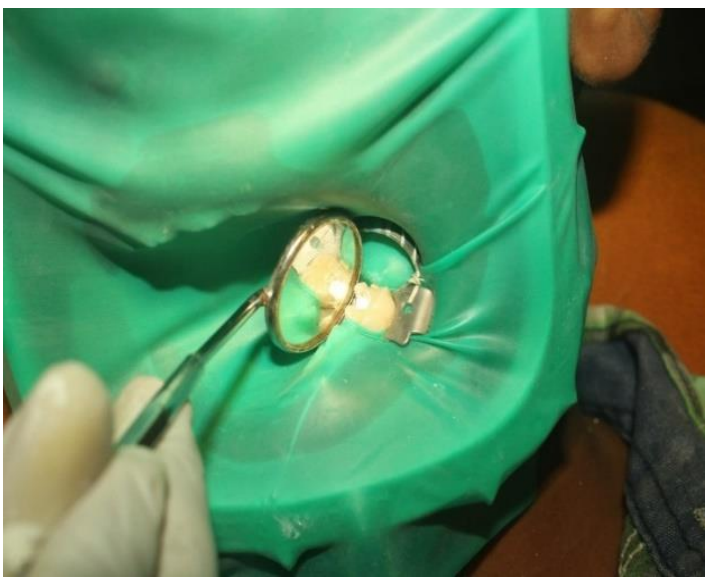

Fig 3e: Restoration done with RMGIC

Group 3: SDF (Silver Diamine Fluoride)

\section{Group 3: Silver Diamine Fluoride group}

Following caries removal, Silver Diamine Fluoride was applied with a micro tip applicator for $15 \mathrm{sec}$ to the floor of the cavity.

Following the placement of the test materials the tooth was subsequently restored with RMGIC to ensure a proper seal in each case.

In all the three groups, after the completion of indirect pulp capping with respective agents, a baseline radiograph was made. Subsequently, at one, three and six months, the tooth was evaluated clinically and radiographically evaluated by taking $\mathrm{x}$ rays. Measurements of the digitized radiographs were performed at baseline, and was done at first, third and sixth months. The increase in dentin thickness was measured using Corel Draw software (Version 17) keeping cement-enamel junction and the highest point on the floor of pulp chamber as reference points and the measurements were made till the base of the restoration. The amount of dentin deposited at each time interval was calculated by the difference in the values obtained from the baseline and follow up radiographs. As the reparative dentine is formed the linear distance between Point A- Point B reduces which inversely reports that there is increase in the reparative dentine which is being formed.

Point A- Point B
Reparative dentine formed

\section{Clinical and Radiographic Evaluation:}

Clinical and radiographic Evaluation was done at the end of $1^{\text {st }}, 3^{\text {rd }}$ and $6^{\text {th }}$ months.

\section{Criteria for clinical success:}

1. No pain

2. No sensitivity to percussion

3. No swelling and/or fistula

4. No pathologic tooth mobility

5. Retention of the restoration (Marginal integrity)

\section{Criteria for radiographic success:}

1. Formation of reparative dentine

2. No radiolucency in periapical or furcation area

3. No widening of periodontal ligament space

4. No external or internal resorption

\section{Statistical Analysis}

The Statistical Analysis were done using SPSS v.22 software IBM., Corp. A descriptive analysis of the data is presented as frequency, mean, and standard deviation (SD).

One-way ANOVA test followed by Tukey's Post hoc Analysis is used to compare the mean thickness of the reparative dentin between the study groups at each time period. Repeated measures of ANOVA will be used to compare the mean difference between different time intervals $\left[1^{\text {st }}\right.$ Month, $3^{\text {rd }}$ Month $\& 6^{\text {th }}$ Month] within the same study group. The level of significance will be set at $\mathrm{P}<0.05$.

\section{Results}

The Results of The Present Study Were Tabulated And 
Analyzed Under The Following Headings.

Table 1: Age and Gender Distribution among study subjects in 03 groups

\begin{tabular}{|c|c|c|c|c|c|c|c|c|}
\hline \multirow{2}{*}{ Variables } & \multirow{2}{*}{ Category } & Group 1 & & Group 2 & & Group 3 & & \multirow{2}{*}{ P-Value } \\
\cline { 3 - 9 } & & Mean & SD & Mean & SD & Mean & SD & \\
\hline \multirow{2}{*}{ Age } & Mean \& SD & 6.9 & 1.4 & 7.6 & 1.3 & 7.4 & 1.1 & \multirow{2}{*}{$0.13^{\mathrm{a}}$} \\
\cline { 2 - 9 } & Range & \multicolumn{2}{|c|}{$5-9$} & \multicolumn{2}{|c|}{$5-9$} & \multicolumn{2}{|c|}{$5-9$} & \\
\hline \multirow{2}{*}{ Gender } & & $\mathrm{n}$ & $\%$ & $\mathrm{n}$ & $\%$ & $\mathrm{n}$ & $\%$ & \\
\cline { 2 - 9 } & Males & 15 & $60 \%$ & 8 & $32 \%$ & 16 & $64 \%$ & \multirow{2}{*}{$0.06^{\mathrm{b}}$} \\
\hline
\end{tabular}

Table 2: The mean distance from point A- point B (in $\mathrm{mm}$ ) between 03 study groups at different time intervals using One-way ANOVA Test

\begin{tabular}{|c|c|c|c|c|c|c|c|c|}
\hline Time & Groups & $\mathbf{N}$ & Mean & SD & Min & Max & $\mathbf{F}$ & P-Value \\
\hline \multirow{3}{*}{ Baseline } & Group 1 & 25 & 0.4302 & 0.1009 & 0.228 & 0.601 & \multirow{3}{*}{2.278} & \multirow{3}{*}{0.11} \\
\hline & Group 2 & 25 & 0.4995 & 0.1406 & 0.315 & 0.795 & & \\
\hline & Group 3 & 25 & 0.4494 & 0.1101 & 0.289 & 0.656 & & \\
\hline \multirow{3}{*}{1 month } & Group 1 & 25 & 0.3294 & 0.0901 & 0.123 & 0.456 & \multirow{3}{*}{12.748} & \multirow{3}{*}{$<0.001 *$} \\
\hline & Group 2 & 25 & 0.4471 & 0.1000 & 0.301 & 0.672 & & \\
\hline & Group 3 & 25 & 0.4481 & 0.1786 & 0.222 & 0.645 & & \\
\hline \multirow{3}{*}{3 months } & Group 1 & 25 & 0.2856 & 0.0895 & 0.119 & 0.443 & \multirow{3}{*}{8.933} & \multirow{3}{*}{$<0.001 *$} \\
\hline & Group 2 & 25 & 0.3946 & 0.1295 & 0.212 & 0.660 & & \\
\hline & Group 3 & 25 & 0.4452 & 0.1779 & 0.220 & 0.637 & & \\
\hline \multirow{3}{*}{6 months } & Group 1 & 25 & 0.2769 & 0.0894 & 0.112 & 0.439 & \multirow{3}{*}{9.081} & \multirow{3}{*}{$<0.001 *$} \\
\hline & Group 2 & 25 & 0.3829 & 0.1369 & 0.170 & 0.655 & & \\
\hline & Group 3 & 25 & 0.4418 & 0.1759 & 0.200 & 0.612 & & \\
\hline
\end{tabular}

Table 3: Comparison of mean distance from point A- point B (in mm) between different time intervals in Group 1 using Repeated measures of ANOVA test

\begin{tabular}{|c|c|c|c|c|c|}
\hline \multirow{2}{*}{ Time } & \multirow{2}{*}{$\mathbf{N}$} & Mean & \multirow{2}{*}{ SD } & \multicolumn{2}{|c|}{ Greenhouse Geisser } \\
\cline { 1 - 1 } & & & & F & P-Value \\
\hline Baseline & 25 & 0.4302 & 0.1009 & & \\
\hline 1 month & 25 & 0.3294 & 0.0901 & \multirow{2}{*}{47.817} & $<0.001 *$ \\
\hline 3 months & 25 & 0.2856 & 0.0895 & & \\
\hline 6 months & 25 & 0.2769 & 0.0894 & & \\
\hline
\end{tabular}

Anova test was done for intragroup comparison at different time intervals in Group 1 The table shows that Group 1 showed there is a highly statistically significant difference $(\mathrm{P}-\mathrm{Value}<0.001 *$ ) at different time interval, that is at the end of one, three and six months.

Table 4: Comparison of mean from point A- point B (in $\mathrm{mm}$ ) between different time intervals in Group 2 using Repeated measures of ANOVA test

\begin{tabular}{|c|c|c|c|c|c|}
\hline \multirow{2}{*}{ Time } & \multirow{2}{*}{ N } & \multirow{2}{*}{ Mean } & \multirow{2}{*}{ SD } & \multicolumn{2}{|c|}{ Greenhouse Geisser } \\
Baseline & 25 & 0.4995 & 0.1406 & F & P-Value \\
\hline 1 month & 25 & 0.4471 & 0.1369 & \multirow{2}{*}{17.948} & $<0.001^{*}$ \\
\hline 3 months & 25 & 0.3946 & 0.1295 & & \\
\hline 6 months & 25 & 0.3829 & 0.1000 & & \\
\hline
\end{tabular}

Anova test was done for intragroup comparison at different time intervals in Group 2 The table shows that Group 2 showed there is a highly statistically significant difference $(\mathrm{P}-$ Value $<0.001 *$ ) at different time interval, that is at the end of one, three and six months.

Table 5: Comparison of mean from point A- point B(in mm) between different time intervals in Group 3 using Repeated measures of ANOVA test

\begin{tabular}{|c|c|c|c|c|c|}
\hline \multirow{2}{*}{ Time } & \multirow{2}{*}{ N } & \multirow{2}{*}{ Mean } & \multirow{2}{*}{ SD } & \multicolumn{2}{|c|}{ Greenhouse Geisser } \\
\cline { 1 - 1 } & & & & F & P-Value \\
\hline Baseline & 25 & 0.4494 & 0.1101 & & \multirow{2}{*}{0.83} \\
\hline 1 month & 25 & 0.4481 & 0.1786 & & \\
\hline 3 months & 25 & 0.4452 & 0.1779 & & \\
\hline 6 months & 25 & 0.4418 & 0.1759 & & \\
\hline
\end{tabular}

Anova test was done for intragroup comparison at different time intervals in Group 3. The table shows that Group 3 showed there is a no statistically significant difference (P-Value 0.83) at different time interval, that is at the end of one, three and six months. 
Table 6: The mean Reparative dentin thickness (in $\mathrm{mm}$ ) between 03 study groups at different time intervals using One-way ANOVA Test

\begin{tabular}{|c|c|c|c|c|c|c|c|c|}
\hline Time & Groups & $\mathbf{N}$ & Mean & SD & Min & Max & $\mathbf{F}$ & P-Value \\
\hline \multirow{3}{*}{$\mathrm{BL}-1 \mathrm{~m}$} & Group 1 & 25 & 0.1008 & 0.1056 & -0.100 & 0.380 & \multirow{3}{*}{6.179} & \multirow{3}{*}{$0.003^{*}$} \\
\hline & Group 2 & 25 & 0.0524 & 0.1268 & -0.090 & 0.400 & & \\
\hline & Group 3 & 25 & 0.0013 & 0.1887 & -0.490 & 0.200 & & \\
\hline \multirow{3}{*}{$B L-3 m$} & Group 1 & 25 & 0.1446 & 0.1055 & -0.090 & 0.380 & \multirow{3}{*}{8.248} & \multirow{3}{*}{$0.001 *$} \\
\hline & Group 2 & 25 & 0.1048 & 0.0419 & 0.010 & 0.280 & & \\
\hline & Group 3 & 25 & 0.0042 & 0.1884 & -0.490 & 0.210 & & \\
\hline \multirow{3}{*}{$B L-6 m$} & Group 1 & 25 & 0.1534 & 0.1061 & -0.090 & 0.390 & \multirow{3}{*}{9.086} & \multirow{3}{*}{$<0.001^{*}$} \\
\hline & Group 2 & 25 & 0.1166 & 0.0481 & 0.000 & 0.280 & & \\
\hline & Group 3 & 25 & 0.0076 & 0.1840 & -0.490 & 0.210 & & \\
\hline
\end{tabular}

One way ANOVA test was used to compare the mean reparative dentin thickness (in $\mathrm{mm}$ ) among the experimental groups at different time intervals. There was highly statistically significant difference among all the three experimental groups at the end of $1^{\text {st }}$ month (P-Value $\left.0.003^{*}\right)$.
There was highly statistically significant difference among all the three experimental groups at the end of $3^{\text {rd }}$ month $(\mathrm{P}-$ Value $\left.0.001^{*}\right)$. There was highly statistically significant difference among all the three experimental groups at the end of $6^{\text {th }}$ month $(\mathrm{P}-$ Value $<0.001 *)$
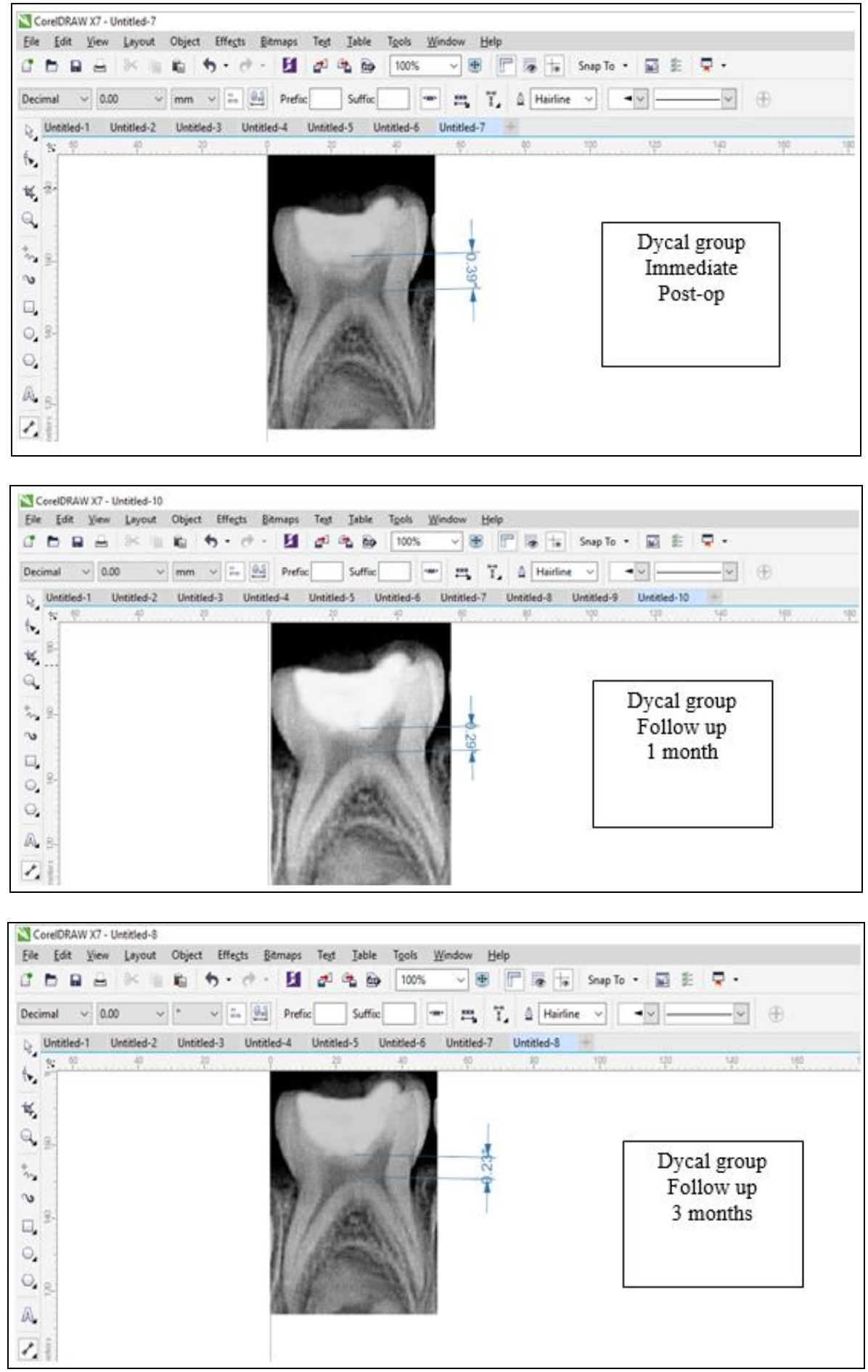


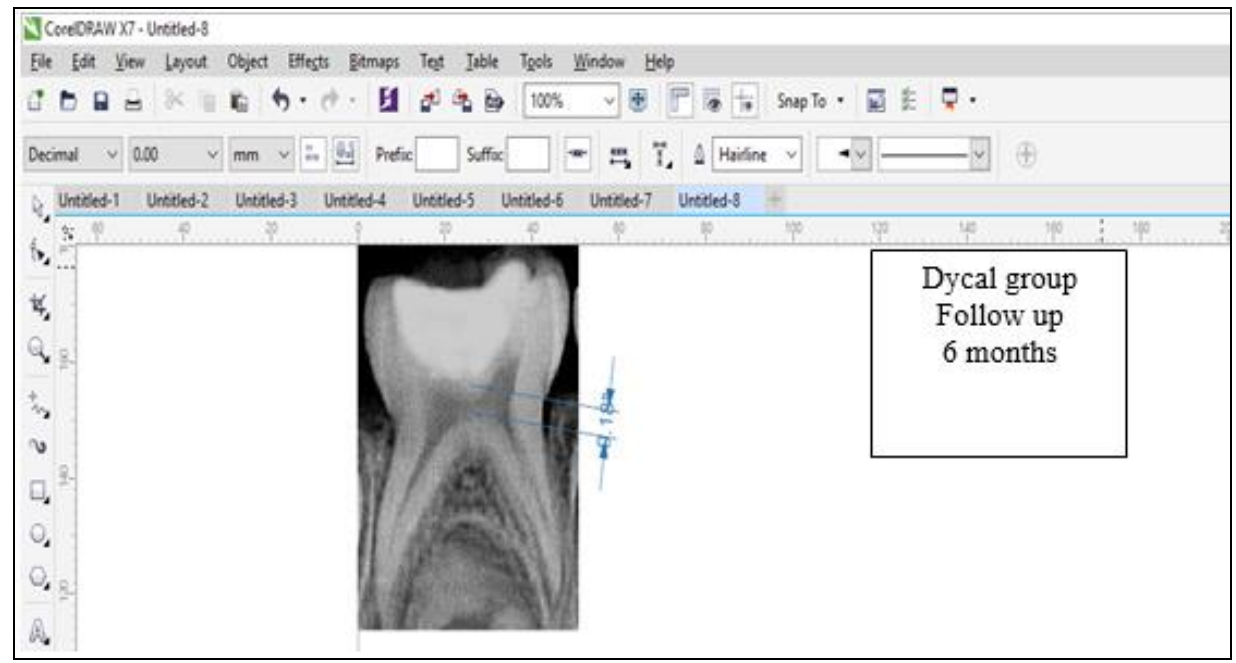

Fig 4: Group 1-Dycal Group
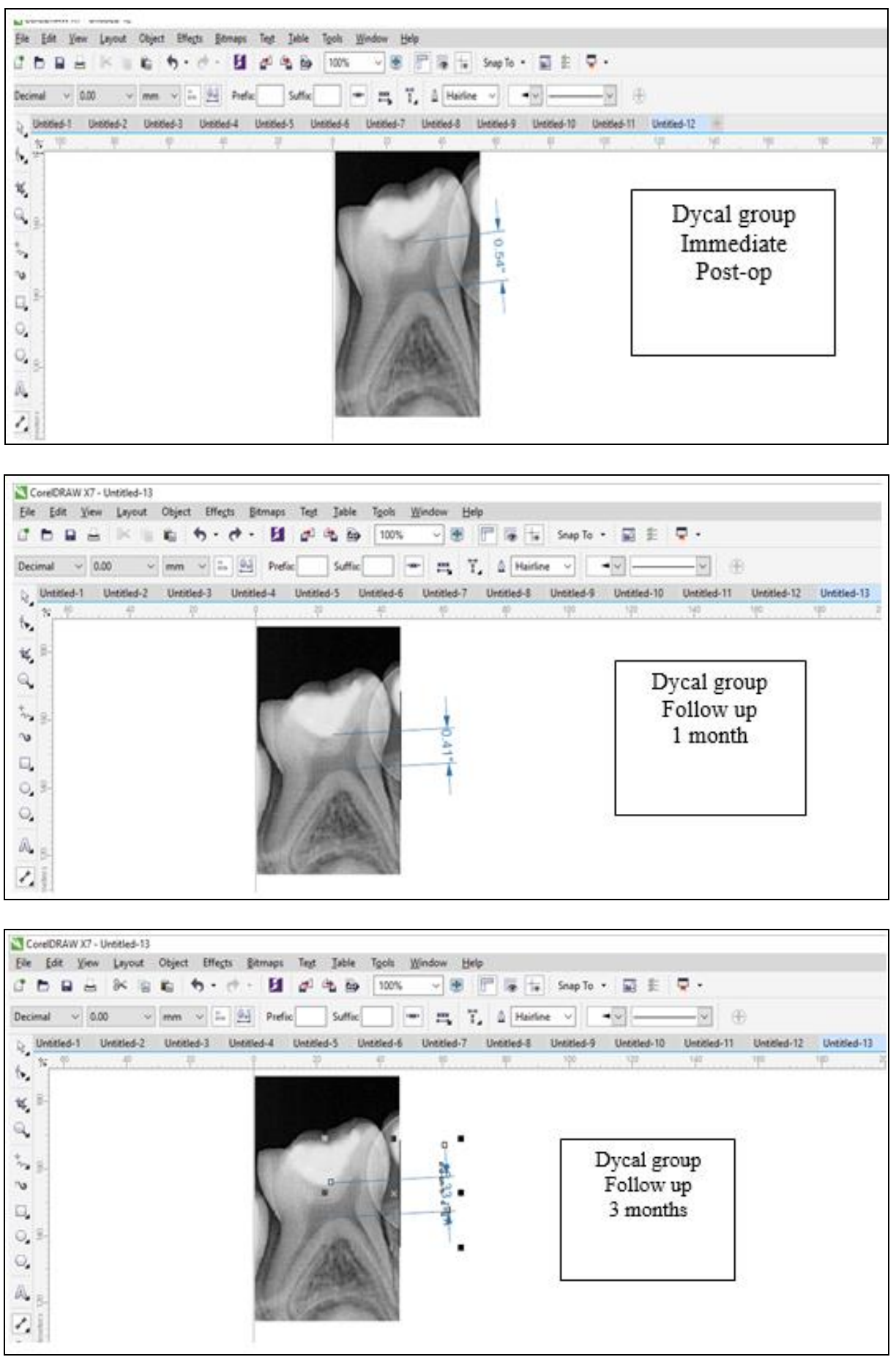


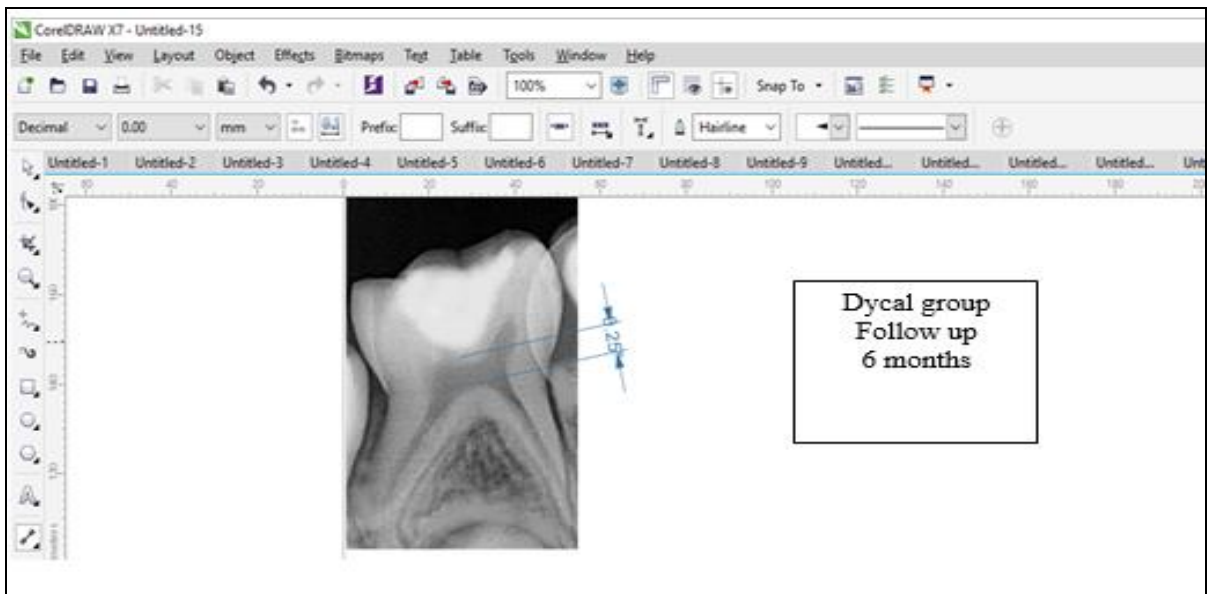

Fig 5: Group 2 - Mta Group
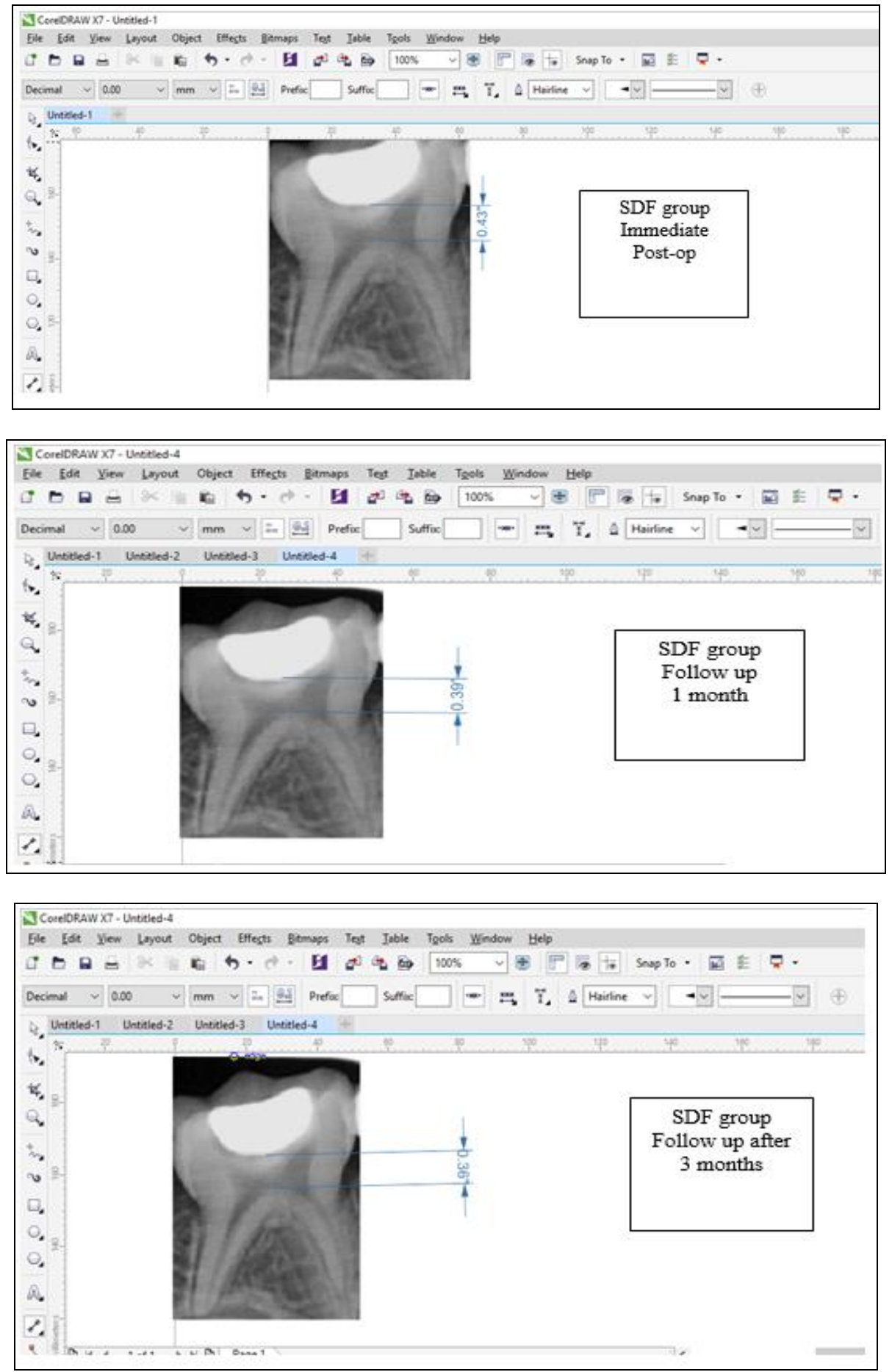


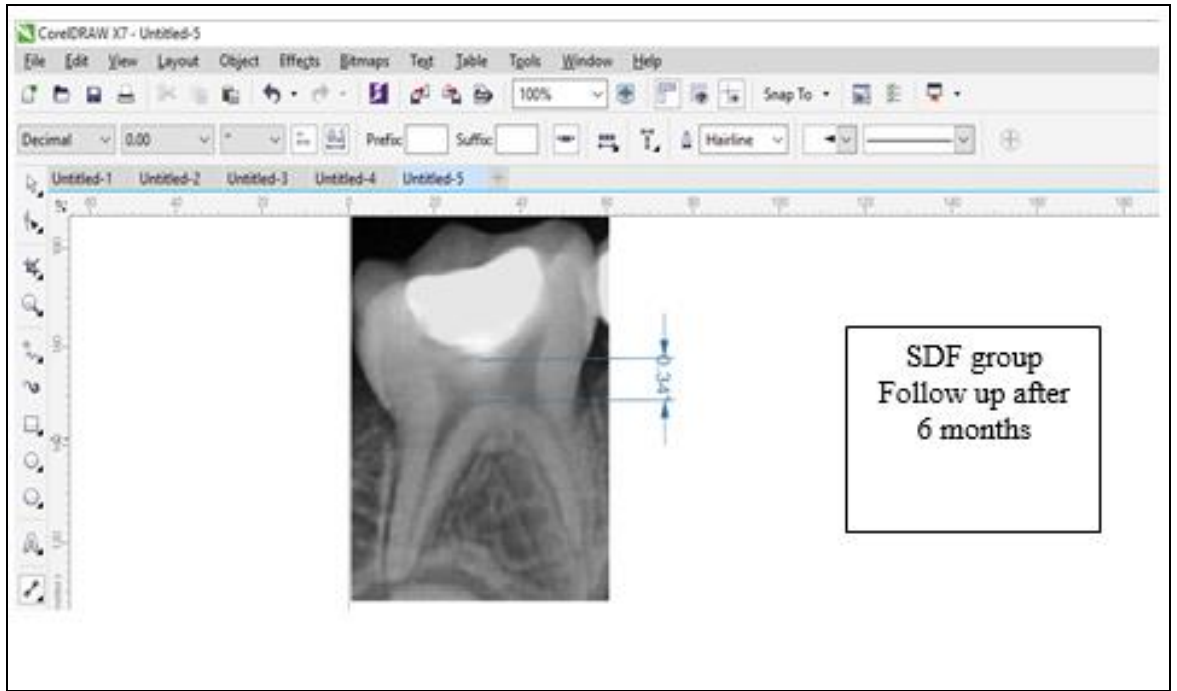

Fig 6: Group 3 - Sdf Group
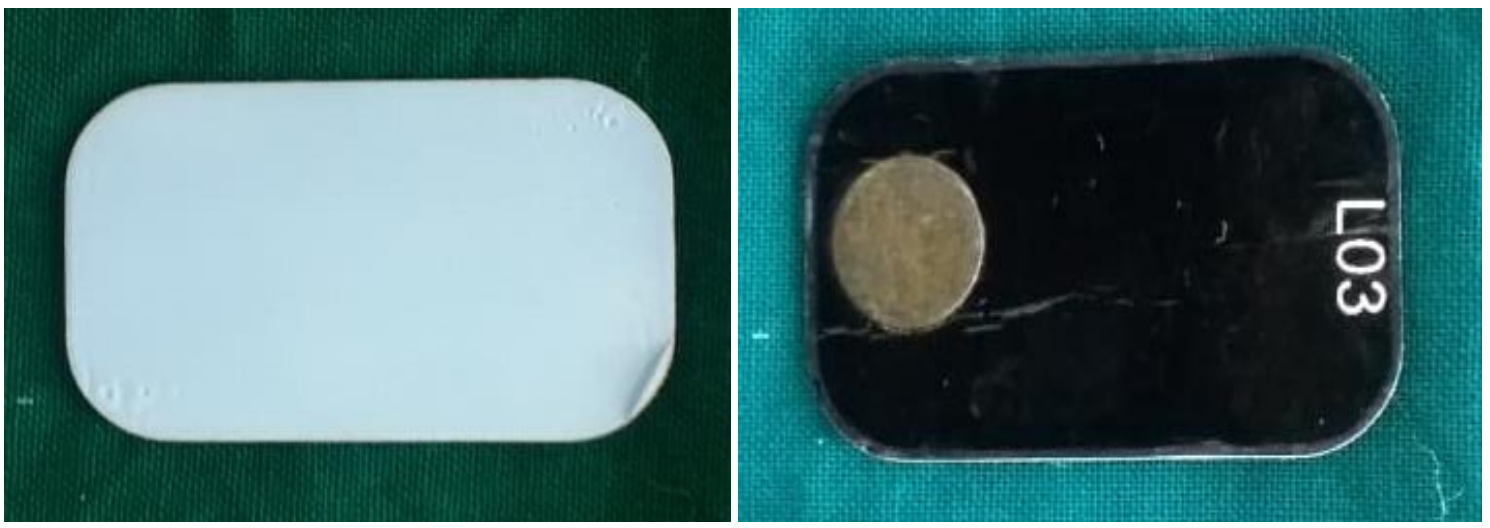

Fig 7: PSP (Phosphor Storage Plates) PLATE

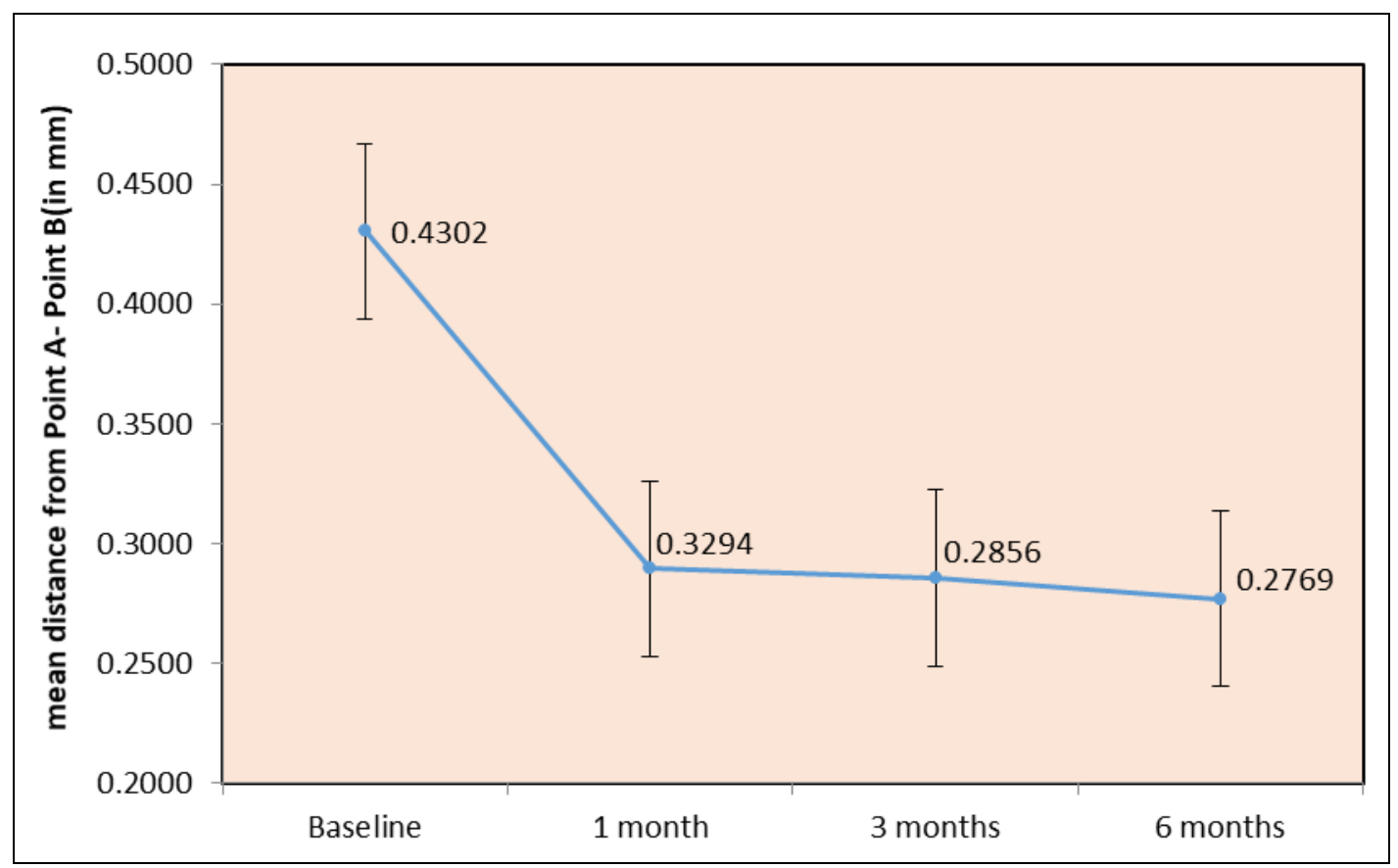

Graph 1: Comparison of mean distance from Point A- Point B(in mm) between different time intervals in Group 1 


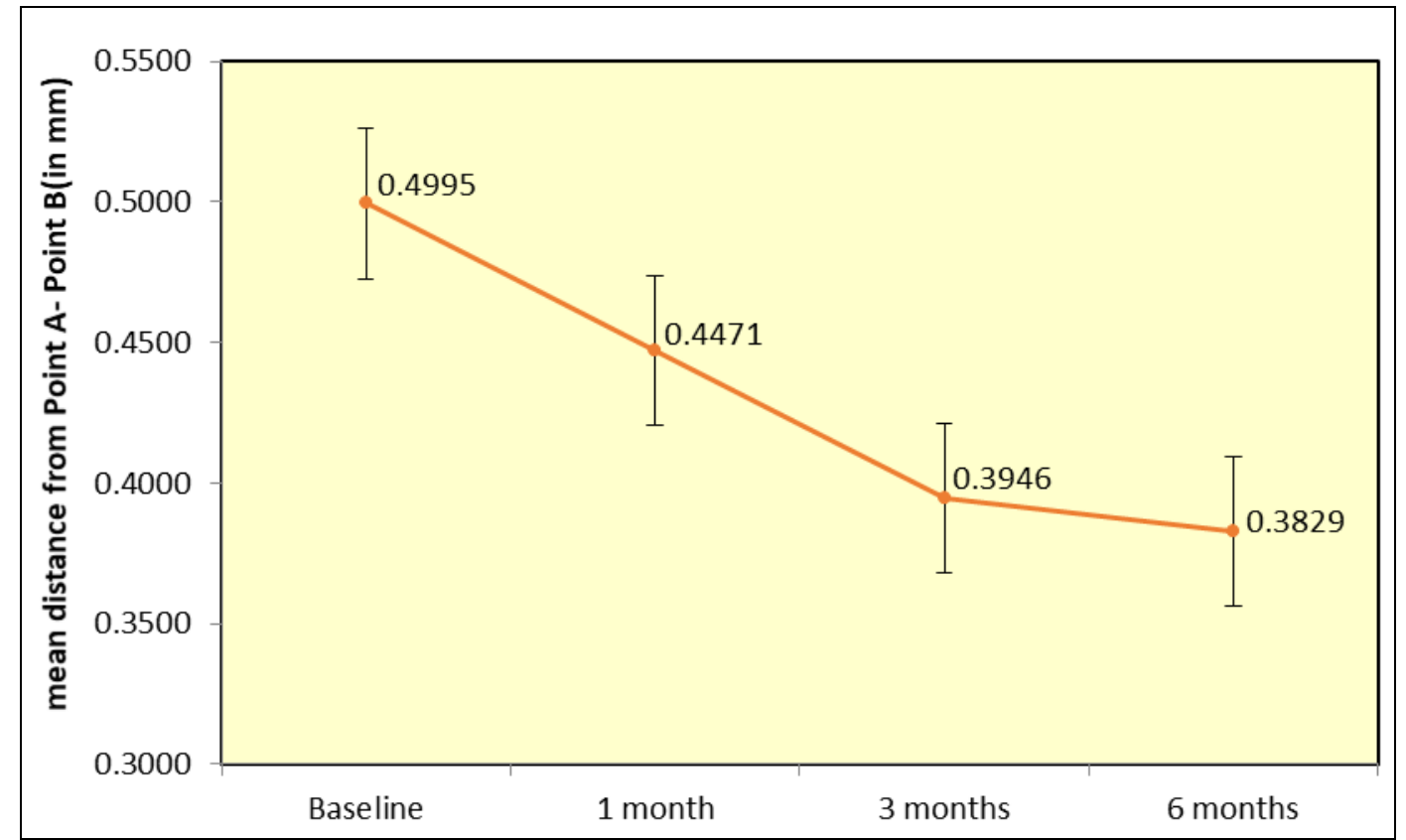

Graph 2: Comparison of mean distance from Point A- Point B(in mm) between different time intervals in Group 2

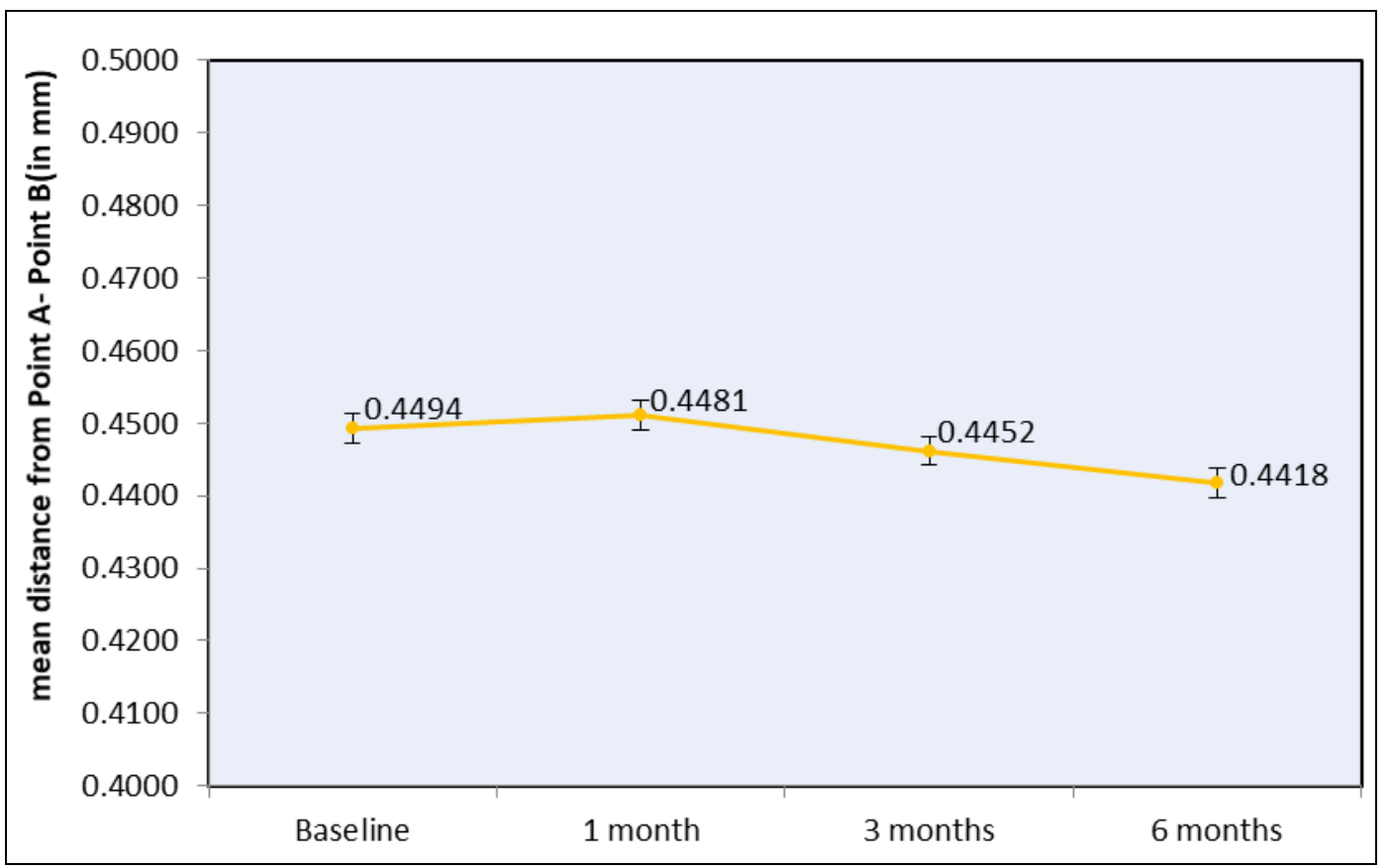

Graph 3: Comparison of mean distance from Point A- Point B (in mm) between different time intervals in Group 3

\section{Discussion}

The rationale for IPT is based on the observation that post mitotic odontoblasts can be induced to up-regulate their synthetic and secretory activities in response to reduced infectious challenge. This results in deposition of tertiary dentine formation which increases the distance between caries and pulp cells by deposition of peritubular dentin which decreases the dentin permeability ${ }^{[14]}$. The rate of reparative dentine formation is $1.4 \mathrm{um} /$ day after cavity preparation. The rate of reparative dentin formation is highest in the $1^{\text {st }}$ month and then diminished with time, it continues upto a period of 912 months but at a slower rate ${ }^{[15]}$.

Since the introduction by Hermann in $1930, \mathrm{Ca}(\mathrm{OH})_{2}$ - based materials have been widely used as therapeutic agents for Indirect Pulp Capping and other procedures. The benefits of $\mathrm{Ca}(\mathrm{OH})_{2}$ include low thermal conductivity, an ability to act as a buffer against the zinc oxide cements commonly used in direct restorations, and the release of hydroxide and calcium ions upon dissolution. The hydroxide ions raise the local $\mathrm{pH}$ to approximately 12 , thereby exerting antimicrobial and antiinflammatory effects. The release of calcium enhances the activity of pyro phosphatase, which aids the maintenance of dentin mineralization and the formation of a dentin bridge.

Certain disadvantages of $\mathrm{Ca}(\mathrm{OH})_{2}$ led to examine newer materials, such as mineral trioxide aggregate (MTA), which displays excellent potential in endodontic applications such as direct pulp capping. However, it has a slower setting time, initial looseness, poor handling characteristics, and is comparatively expensive.

The search for an ideal material for lining deep cavities is a matter of ongoing research. Need to evaluate different types of materials clinically and compare them with each other cannot be overemphasized. While calcium hydroxide and MTA has been extensively used in the past for IPT procedure, high fluoride releasing materials like Silver Diamine Fluoride (SDF) is proposed newer IPT material which stimulates the 
formation of reparative dentin. Silver Diamine Fluoride (SDF) was initially used as a cariostatic agent. Various clinical studies [4] have reported its utility in the treatment and prevention of caries. SDF helps in the deposition of silver phosphate to restore mineral content, resulting in rehardening of tooth structure. It also releases fluoride ${ }^{[16]}$. A 38\% SDF product has been accepted as a therapeutic agent by the Central Pharmaceutical Council of the Ministry of Health and Welfare of Japan for dental treatment for half a century ${ }^{[17]}$.

In the present study, the selection of the cases were done based on the clinical and radiographic criteria for IPT. Ricucci et al. correlated clinical and radiographic evaluation of pulp status with histologic classification of pulp conditions and revealed a good agreement especially for cases with no pulpal diseases or irreversible disease ${ }^{[18]}$.

As the reparative dentine is formed the linear distance between Point A- Point B reduces which inversely reports that there is increase the reparative dentine which is being formed.

Point A- Point B Reparative dentine formed

The results of our study revealed that, the mean distance between point A- point B at the baseline in Dycal group was $0.4302 \mathrm{~mm}$. On intra-group comparison of Dycal group the distance by the end of $1^{\text {st }}$ month it was recorded as 0.3294 $\mathrm{mm}$ and by the end of 3 months it was $0.2856 \mathrm{~mm}$. By the end of 6 months the distance has reduced to $0.2769 \mathrm{~mm}$ therefore the reparative dentine formed was around $0.1533 \mathrm{~mm}$ by the end of 6 months from baseline.

An in vivo study was conducted by George et al. evaluating the efficacy of Dycal as IPT material for a period of 6 months. By the end of 6 months the material showed deposition of reparative dentine about $0.097 \mathrm{~mm}$ and had $100 \%$ success rate. The study concluded that both clinically and radiographically Dycal has proven to be a good IPT material for primary teeth ${ }^{[19]}$. In another study by of Leye Benoist et al., showed $0.085 \mathrm{~mm}$ of increase in dentin thickness over a period of 6 months ${ }^{[20]}$. These two studies were in accordance with our study.

Mechanism of Tertiary dentin deposition in response to calcium hydroxide is mediated via alkaline phosphatase enzyme, stimulated by hydroxyl ions at $\mathrm{pH} 10.2$ and calciumdependent pyro-phosphatase. Heithersay suggested that calcium ions reduce the permeability of capillaries so that less interstitial fluid is produced, thus calcium ions concentrate at the mineralization site. The mineral deposition is presumably by calcium derived from the blood supply of the dental pulp. This indicates that calcium hydroxide is an initiator rather than a substrate for Tertiary dentin deposition. Calcium hydroxide showed Tertiary dentin deposition in lesser number of specimens at 6 weeks, probably indicating that it requires longer time to respond to calcium hydroxide when used as IPT material ${ }^{[13]}$.

The mean distance between point A- point B at the baseline in MTA group was $0.4995 \mathrm{~mm}$. On intra-group comparison of MTA the mean distance at the end of $1^{\text {st }}$ month it was recorded as $0.4471 \mathrm{~mm}$ and by the end of 3 months it is $0.3946 \mathrm{~mm}$. By the end of 6 months the distance has reduced to $0.3829 \mathrm{~mm}$ therefore the amount of reparative dentine formed at the end of 6 months is around $0.116 \mathrm{~mm}$.

Leye Benoist et al. ${ }^{[20]}$ showed $0.121 \mathrm{~mm}$ of increase in dentin thickness over 6 months when MTA was used an IPT material for 30 primary molars for a period of 6 months. The values of dentinogensis quoted by various authors in the above mentioned studies are in par with the present study.

The intragroup comparison of SDF group in this study, revealed an average distance from point A-point B of $0.4494 \mathrm{~mm}$ by the end of $1^{\text {st }}$ month it was recorded as 0.4481 $\mathrm{mm}$ and by the end of 3 months it was $0.4452 \mathrm{~mm}$. By the end of 6 months the distance had reduced to $0.4418 \mathrm{~mm}$ therefore the reparative dentine formed at the end of 6 months was around $0.0076 \mathrm{~mm}$ this gives a statistically insignificant PValue of 0.83 . However there was no further progression of caries both clinically and radiographically.

Nakade $e t$ al. stated that fluoride at micromolar concentrations can stimulate the proliferation and alkaline phosphatase activity of human dental pulp cells ${ }^{[21]}$. Fluoride at this level stimulated thymidine incorporation into DNA in dental pulp cells, with optimal effects around $50 \mu \mathrm{Mol}$. It significantly increased the alkaline phosphatase activity in dental pulp cells by $177 \pm 12 \%$. Extracellular-matrix synthesis (Type I collagen) was also shown to increase by $150 \pm 8.7 \%$. This suggests that fluoride at low concentrations can be a useful therapeutic agent, where increased Tertiary dentin is desired, such as in IPT procedure. It can be hypothesized that SDF can stimulate the Tertiary dentin when used as an IPT material.

However in our study SDF did not show reparative dentin formation to an extent that was statistically significant. According to Flaster et al. and Maltz et al. the indirect pulp capping is not considered a material-dependent technique. The role of the lining material is not essential, but a good marginal seal, preventing, (i) bacterial substrate infiltrating the dentin, (ii) the control of the carious activity. These criteria guarantees a high success of IPT ${ }^{[22,23]}$.

Yamaga and his co-workers suggest that both fluoride ions and silver ions contribute to its mechanism of action ${ }^{[17]}$. They propose that fluoride ions act mainly on tooth structure while silver ions act mainly on cariogenic bacteria.

Mei and her co-workers found that SDF provides an alkaline environment to render $\mathrm{CaF} 2$ less soluble and, therefore, serves as a fluoride reservoir for acid challenges by cariogenic bacteria [24]. In vitro studies show that SDF can inhibit demineralisation of hydroxyl apatite and preserve collagen from degradation in demineralised dentine tissue ${ }^{[24]}$. In addition, collagen breakdown of dentine was significantly reduced ${ }^{[25]}$, and dentine hardness was significantly increased after SDF application. SDF also has antibacterial properties. Silver ions can bind with negatively charged peptidoglycans in bacterial cell walls and disrupt membrane transport function, which in turn leads to cellular distortions and loss of viability ${ }^{[26]}$. Binding to sulphydryl groups (thio group of cystine), which is essential for enzyme activities, can inhibit bacterial enzyme activities, disrupt metabolic processes, and eventually cause death of the microbe ${ }^{[27]}$.

In our study SDF placed as IPT material and followed up for 6 months did not show any adverse pulp reactions. In a study by Korwar et al. ${ }^{[13]}$ SDF was tested for an IPT material invivo. The study reports that out of 9 specimens which received SDF as IPT material for a period of 6 weeks 5 specimens showed reparative dentin formation while 4 did not show any odontoblastic formation in histopathological section. However none of them showed any adverse pulpal reactions which is in accordance with our findings.

\section{However the limitations of the study included}

1. Sufficient (setting) time was not given between the 
placement of MTA and the access fill material which could have affected the reparative dentine formation with MTA.

2. SEM and Histopathological investigations would have provided a better insight towards the exact mechanism of SDF.

\section{Within the limitation of the study, the following conclusions were drawn}

1. All the three experimental materials Dycal, MTA, SDF showed reparative dentin formation at the end of 1,3 and 6 months.

2. Although SDF did not show significant amount of reparative dentin formation compared Dycal and MTA. It still seems to be a good IPT material as it fulfils the other criteria for IPT procedure such as good biological seal and maintenance of the pulp vitality.

3. Thus SDF can be used as an alternative IPT material in severe ECC cases and in un co-operative children.

\section{Reference}

1. American Academy on Pediatric Dentistry Clinical Affairs Committee-Pulp Therapy subcommittee, American Academy on Pediatric Dentistry Council on Clinical Affairs. Guideline on pulp therapy for primary and young permanent teeth. Pediatr Dent. 2008 2009;30(7):170-4.

2. Qureshi A, ES, Nandakumar Null, Pratapkumar Null, Sambashivarao Null. Recent advances in pulp capping materials: an overview. J Clin Diagn Res JCDR 2014;8(1):316-21.

3. Mohammadi Z, Dummer P. Properties and Applications of Calcium Hydroxide in Endodontics and Dental Traumatology 2011;44:697.

4. Shen Q, Sun J, Wu J, Liu C, Chen F. An in vitro investigation of the mechanical-chemical and biological properties of calcium phosphate/calcium silicate/bismutite cement for dental pulp capping. J Biomed Mater Res B Appl Biomater 2010;94B(1):141-8.

5. Schuurs AHB, Gruythuysen RJM, Wesselink PR. Pulp capping with adhesive resin-based composite vs. calcium hydroxide: a review. Dent Traumatol. 2000;16(6):240-50.

6. Stanley HR. Pulp capping: Conserving the dental pulpCan it be done? Is it worth it? Oral Surg Oral Med Oral Pathol. 1989;68(5):628-39.

7. Camilleri J, Pitt Ford TR. Mineral trioxide aggregate: a review of the constituents and biological properties of the material. Int Endod J 2006;39(10):747-54.

8. Peng JJ-Y, Botelho MG, Matinlinna JP. Silver compounds used in dentistry for caries management: a review. J Dent 2012;40(7):531-41.

9. Chu CH, Mei L, Seneviratne CJ, Lo ECM. Effects of silver diamine fluoride on dentine carious lesions induced by Streptococcus mutans and Actinomyces naeslundii biofilms. Int J Paediatr Dent 2012;22(1):2-10.

10. Mei ML, Ito L, Cao Y, Lo ECM, Li QL, Chu CH. An ex vivo study of arrested primary teeth caries with silver diamine fluoride therapy. J Dent. 2014;42(4):395-402.

11. Sharma G, Puranik MP, KRS. Approaches to Arresting Dental Caries: An Update. J Clin Diagn Res JCDR. 2015;9(5):ZE08-11.

12. Contreras V, Toro MJ, Elías-Boneta AR, EncarnaciónBurgos A. Effectiveness of silver diamine fluoride in caries prevention and arrest: a systematic literature review. Gen Dent 2017;65(3):22-9.
13. Korwar A, Sharma S, Logani A, Shah N. Pulp response to high fluoride releasing glass ionomer, silver diamine fluoride, and calcium hydroxide used for indirect pulp treatment: An in-vivo comparative study. Contemp Clin Dent 2015;6(3):288-92.

14. Bjørndal L, Larsen T, Thylstrup A. A clinical and microbiological study of deep carious lesions during stepwise excavation using long treatment intervals. Caries Res 1997;31(6):411-7.

15. Singhal M, Chaudhary CP, Anand R, Singh N, Sahni T. Recent Advancements Of Indirect Pulp Capping In Primary Teeth: A Review. J Adv Med Dent Sci Res. 2015;3(5):5.

16. Gupta A, Sinha N, Logani A, Shah N. An ex vivo study to evaluate the remineralizing and antimicrobial efficacy of silver diamine fluoride and glass ionomer cement type VII for their proposed use as indirect pulp capping materials - Part I. J Conserv Dent JCD 2011;14(2):113-6.

17. Yamaga R, Nishino $M$, Yoshida S, Yokomizo I. Diammine silver fluoride and its clinical application. J Osaka Univ Dent Sch 1972;12:1-20.

18. Naseri M, Khayat A, Zamaheni S, Shojaeian S. Correlation between Histological Status of the Pulp and Its Response to Sensibility Tests. Iran Endod J. 2017;12(1):20-4.

19. George V, Janardhanan SK, Varma B, Kumaran P, Xavier AM. Clinical and radiographic evaluation of indirect pulp treatment with MTA and calcium hydroxide in primary teeth (in-vivo study). J Indian Soc Pedod Prev Dent 2015;33(2):104.

20. Leye Benoist F, Gaye Ndiaye F, Kane AW, Benoist HM, Farge P. Evaluation of mineral trioxide aggregate (MTA) versus calcium hydroxide cement (Dycal(囚) ) in the formation of a dentine bridge: a randomised controlled trial. Int Dent J 2012;62(1):33-9.

21. Nakade O, Koyama H, Arai J, Ariji H, Takada J, Kaku T. Stimulation by low concentrations of fluoride of the proliferation and alkaline phosphatase activity of human dental pulp cells in vitro. Arch Oral Biol. 1999;44(1):8992.

22. Falster CA, Araujo FB, Straffon LH, Nör JE. Indirect pulp treatment: in vivo outcomes of an adhesive resin system vs calcium hydroxide for protection of the dentinpulp complex. Pediatr Dent 2002;24(3):241-8.

23. Cannon M, Gerodias N, Viera A, Percinoto C, Jurado R. Primate pulpal healing after exposure and TheraCal application. J Clin Pediatr Dent 2014;38(4):333-7.

24. Mei ML, Chu CH, Lo ECM, Samaranayake LP. Fluoride and silver concentrations of silver diammine fluoride solutions for dental use. Int $\mathbf{J}$ Paediatr Dent 2013;23(4):279-85.

25. Mei ML, Li QL, Chu CH, Yiu CKY, Lo ECM. The inhibitory effects of silver diamine fluoride at different concentrations on matrix metalloproteinases. Dent Mater Off Publ Acad Dent Mater 2012;28(8):903-8.

26. Coward JE, Carr HS, Rosenkranz HS. Silver sulfadiazine: effect on the ultrastructure of Pseudomonas aeruginosa. Antimicrob Agents Chemother 1973;3(5):621-4.

27. Russell AD, Hugo WB. Antimicrobial activity and action of silver. Prog Med Chem 1994;31:351-70. 